\title{
Infância em Berlim - uma autobiografia anônima de Walter Benjamin
}

Georg Otte

Universidade Federal de Minas Gerais

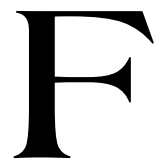

az parte dos chavões sobre a infância a idéia de o universo da criança ser um "mundo mágico" ou "encantado". Basta dar uma olhada nos nomes das lojas de artigos infantis ou das próprias creches para se ter uma confirmação desses chavões: a magia e o encantamento fazem parte da encenação do mundo infantil a partir de uma postura um tanto melancólica dos adultos, pois as ilusões encantadas dos primeiros anos de vida tiveram que ceder ao desencantamento e às desilusões de um mundo racionalizado e competitivo.

A suposta magia da infância, portanto, é resultado de uma projeção que parte da sensação de uma perda, de um paraíso perdido em que teriam reinado paz e harmonia. E da mesma maneira que Adão e Eva foram expulsos do Paraíso por terem comido do fruto da árvore do conhecimento, o adulto, depois de ter cometido o pecado original de adquirir conhecimentos e cultura, ao invés de contabilizar os ganhos alcançados, muitas vezes passa a lamentar sua "expulsão" da infância, isto é, a substituição do estado poético e natural pelo prosaico e cultural, impondo aos próprios filhos uma 'magia' que ele mesmo deixou para trás.

A dominação da natureza pela cultura, inclusive da própria natureza humana, durante muito tempo celebrada como avanço, significou ao mesmo tempo um distanciamento e uma alienação dela. De certa maneira, Descartes transforma a expulsão do Paraíso numa virtude do homem moderno quando chega à conclusão de que a única prova para nossa existência é a nossa capacidade de pensar (Cogito ergo sum - Penso logo sou) e quando estabelece uma oposição entre o homem enquanto "coisa pensante" (res cogitans) e o mundo enquanto "coisa extensa" (res extensa). Ou seja, o mundo não apenas deixa de ter uma qualidade espiritual - como no caso 
dos espíritos do homem dito "primitivo" -, mas o homem também passa a desprezar suas qualidades físicas. Nas Meditações cartesianas, o corpo é a primeira instância a ser superada na escalada rumo ao Cogito, pois os cinco sentidos "brincam" conosco, zombam da nossa inteligência, tornando-nos vítimas do seu jogo. Por isso, para afirmarmos como sujeitos pensantes e autônomos no sentido cartesiano, precisamos de uma "desilusão de ótica" e superar a zombaria dos sentidos através de uma razão pura, que seria a única garantia para um pensamento confiável.

No entanto, o homem "somente é homem pleno quando joga", como já preconizava Schiller, ${ }^{1}$ chamando de "bárbaro" ${ }^{2}$ aquele que reprimia sua vida sensitiva em nome da razão. Escrita no auge do Iluminismo, que, de certa maneira é o ponto extremo do cartesianismo, a Educação Estética do Homem de Schiller pode ser vista como uma das primeiras tentativas de resgatar o corpo como parte integral do ser humano. O jogo, tradicionalmente considerado como uma atividade da criança, passa a ser o modelo de uma nova antropologia por reunir as capacidades sensoriais e intelectuais numa única atividade que, por sua vez, serviria como base da atividade artística. Essa educação não é "estética" por ensinar o que é belo e o que não o é, mas - fiel à raiz grega da palavra - por dar valor à percepção sensorial. A valorização do jogo na "Educação estética" significa o resgate dos sentidos, isto é, da própria natureza humana, e se não chega a proporcionar a volta ao Paraíso, oferece pelo menos uma saída da alienação cultural.

Evidentemente, as sociedades ocidentais tiveram que esperar mais um século até que a suposta superioridade da razão ficasse definitivamente abalada. A filosofia de Nietzsche e a Psicanálise de Freud podem ser vistas como as marcas principais da derrota da razão que teve sua última etapa gloriosa no Positivismo do século XIX. No seu famoso ensaio "O mal-estar na cultura", ${ }^{3}$ Freud admite que, por um lado, a cultura gerou meios para a "proteção contra a natureza" e a "administração das relações humanas", ${ }^{4}$ mas levanta, por outro lado, seu aspecto mais negativo, a saber, o fato de ela se basear no Triebverzicht, literalmente na "renúncia às pulsões", 5 isto é, na

\footnotetext{
${ }^{1}$ FRIEDRICH, 1990, p. 84.

${ }^{2}$ FRIEDRICH, 1990, p. 33.

3 SIGMUND, 1974. Trad. nossa.

${ }^{4}$ SIGMUND, 1974, p. 220.

5 SIGMUND, 1974, p. 227.
} 
renúncia à satisfação da própria natureza pulsional, principalmente da própria natureza sexual.

A idéia da renúncia marca também o estudo "Protestantismo ascético e espírito capitalista", de Max Weber, contemporâneo de Freud. Na visão protestante, o trabalho e o decorrente sucesso econômico não apenas serviriam para o indivíduo mostrar que usufrui a graça de Deus, mas também exige abstinência sexual, ${ }^{6}$ que, como em Freud, seria o preço a ser pago pelas conquistas culturais. O racionalismo, filosoficamente fundado por Descartes, se reflete socialmente por uma crescente racionalização, a palavra-chave da sociologia weberiana. Mesmo se Weber, fiel ao seu próprio ideal da Wertfreiheit, da isenção de juizos de valor, evitou qualquer julgamento em relação à racionalização, não há dúvida de que ele tinha consciência de que o preço pago pelos ganhos alcançados era muito alto, motivo pelo qual ele passou a dar preferência ao termo desencantamento:

A crescente intelectualização e racionalização, portanto, significa [...] que, em princípio, não existem poderes secretos e imprevisíveis [...], mas que - em princípio - tudo pode ser dominado através do cálculo. Isso, no entanto, significa: desencantamento do mundo. Não se recorre mais, como o selvagem, para quem existiam esses poderes, a meios mágicos para dominar os espíritos ou para pedir-lhes alguma coisa, mas são os meios técnicos e o cálculo que resolvem isso.?

O encantamento e a magia, portanto, não são um privilégio da infância, mas pertencem, segundo Weber, também a um determinado estágio na evolução humana. A criança só não prossegue no seu mundo mágico porque a socialização por pais e professores costuma ter como meta um ser humano predominantemente racional e degradar a educação do corpo e dos sentidos a atividades de lazer. E as nossas escolas, herdeiros do espírito iluminista e positivista, fazem de tudo para perpetuar a criação do que Schiller chamaria de novos "bárbaros".

Walter Benjamin não era apenas contemporâneo de Freud e Weber, mas seu "anti-subjetivismo"8 radical deixou claro que sua obra também fazia

\footnotetext{
${ }^{6}$ WEBER, 1992, p. 360.

7 WEBER, 1992, p. 317; grifo de M.W. Trad. nossa.

8 Theodor W. Adorno apud TIEDEMANN, 1983. p. 13, nota 5.
} 
parte do 'enterro' do Cartesianismo. Ele não apenas atacava duramente o Positivismo e o Historicismo, mas os seus ensaios clássicos como "A obra de arte na era de sua reprodutibilidade técnica" e "O Narrador", aparentemente muito distantes entre si pela temática e pela abordagem da mesma, mostram que sua preocupação principal não é com a excelência do sujeito racional, nem com um sujeito revolucionário como sugere o credo marxista no início do primeiro ensaio, mas com a inserção mais ou menos bem-sucedida do sujeito físico no seu confronto com um mundo às vezes estranho e ameaçador.

A adesão verbal ao marxismo e a exigência espectacular da destruição da aura que fez tanto sucesso na época do anti-autoritarismo estudantil encobriu por muito tempo um aspecto do ensaio sobre a reprodutibilidade técnica da obra de arte que poderia ser chamado de antropológico. Assim, Benjamin chega até a estabelecer um paralelismo entre a era do cinema e o mundo pré-histórico, quando a obra de arte tinha como função a mediação entre o homem e seu meio e quando esta mediação acontecia através de manifestações da arte primitiva, ou seja, através de forças mágicas atribuídas à representação de animais de caça, sendo que o próprio ato de representar era uma maneira de vencer as adversidades naturais. A analogia constatada por Benjamin se baseia no pressuposto de o mundo técnico ser tão desconhecido e hostil para o homem moderno quanto a natureza o era para o homem primitivo. Como o homem pré-histórico, o homem contemporâneo do século XX recorreria à arte para enfrentar o mundo técnico que guarda todas as ameaças de uma "segunda natureza":?

Mas essa técnica emancipada se confronta com a sociedade moderna sob a forma de uma segunda natureza, não menos elementar que a da sociedade primitiva, como provam as guerras e as crises econômicas. Diante dessa segunda natureza, que o homem inventou mas há muito não controla, somos obrigados a aprender, como outrora diante da primeira. Mais uma vez, a arte põe-se a serviço do aprendizado. ${ }^{10}$

9 Cf. também Das Passagen-Werk, p. 576: "Só um observador desatento pode negar que há um jogo de correspondências entre a técnica moderna e o mundo arcaico dos símbolos."

10 WALTER, 1985, p. 174. 
"Mais uma vez" quer dizer que a arte, depois de passar por um processo de isolamento social, volta a assumir o papel de mediadora, aproximando o homem do seu mundo. À maneira do aprendiz de magia (Zauberlehrling) do poema homônimo de Goethe, o ser humano não controla o mundo técnico que criou, não conseguindo mais se livrar dos espíritos que chamou (Die ich rief, die Geister,/Werd ich nun nicht los). A segunda natureza da técnica é um mundo tão hostil quanto o pré-históricos com seus perigos, e, ao contrário de Weber, segundo o qual o homem confia na racionalidade do mundo que o cerca, Benjamin, nesse ponto mais próximo de Freud, destaca sua estranheza.

Entretanto, não são mais as forças mágicas que, através da arte, ajudam a superar os perigos da caça, mas o "aprendizado" que, segundo Benjamin, o cinema estaria oferecendo. A partir dessa perspectiva antropológica, o isolamento da obra de arte e a demarcação deste isolamento pela aura aparecem como um desvio da verdadeira função da arte, que, segundo Benjamin, seria seu papel mediador. O termo da "segunda natureza", portanto, faz parte do projeto benjaminiano não apenas de reintegrar a arte no mundo presente, mas de o ser humano assimilar seu mundo por meio dela.

No seu ensaio "O narrador", Benjamin também recorre a uma argumentação antropológica quando confere à narrativa uma função mediadora no confronto entre o ser humano e seu ambiente e quando analisa esse confronto nas diversas situações macro-históricas. Não é por acaso que muitos contos de fada - segundo Benjamin um dos protótipos da narrativa - são Odisséias em miniatura, cujos heróis, à maneira de Ulisses, vencem as mais diversas ameaças graças à sua coragem e astúcia. A "sensação de felicidade" causada pela narrativa não deixa de ser também uma felicidade ex negativo, pois, se o interesse pela narrativa se alimenta da esperança de "libertar-se do pesadelo mítico", ela aponta, ao mesmo tempo, para a existência desse mesmo pesadelo e para o fato de ele representar uma ameaça permanente. Escutar a narrativa de lugares distantes é uma maneira de se assegurar da solidariedade humana, e narrar a mesma narrativa no mesmo lugar não significa apenas conservá-la através do tempo, mas fortificar os laços que unem as gerações sucessivas. Além de ser um instrumento para superar distâncias, a narrativa se revela como uma espécie de escudo que protege não só a comunidade "artesanal" reunida a sua volta, mas todo o gênero humano.

A própria analogia entre a infância do indivíduo e os tempos préhistóricos da humanidade tem uma longa história, sendo associada, no 
contexto literário alemão, principalmente à figura de Herder. ${ }^{11}$ Infância em Berlim retoma essa analogia, pois o mundo dessa infância é um mundo mágico stricto sensu, não no sentido das projeções de Walt Disney ou outros fabricantes de paraisos perdidos, mas por uma associação direta com o homem das cavernas, ou seja, dos caçadores coletores da pré-história. No episódio "Caçando borboletas" podemos ler o seguinte:

Com a rede levantada, esperava tão-só que o encanto, que parecia se operar da flor para aquele par de asas, cumprisse sua tarefa [...] Se uma vanessa ou uma esfinge [tipos de borboletas; N.T.], que comodamente poderia ter alcançado, zombasse de mim com vacilações, oscilações e flutuações, então teria querido dissolver-me em luz e em ar a fim de me aproximar da presa sem ser notado e poder dominá-la. E esse desejo se fazia tão real, que lufavam sobre mim, que me irrigavam, cada agitar e cada oscilar de asas, pelos quais me apaixonava. Entre nós começava a se impor o antigo estatuto da caça: quanto mais assumia intimamente a essência da borboleta, tanto mais ela adotava em toda ação o matiz da decisão humana, e, por fim, era como se sua captura fosse o único preço pelo qual minha condição de homem pudesse ser reavida. ${ }^{12}$

No mundo mágico povoado por poderes misteriosos, não apenas se diluem as demarcações entre os seres da natureza, mas também entre o sujeito caçador e sua presa. A magia desse episódio ainda não degenerou para um clichê de beleza, mas se refere mesmo às artimanhas da transformação e ao jogo de ilusões no qual o caçador se torna facilmente o caçado e onde o animal e humano, o objeto e o sujeito da caça se misturam. Só o ato bruto da captura põe fim a esse jogo de ambigüidades, restabelecendo a soberania do sujeito-caçador do menino.

Cabe lembrar que essa captura se deve ao uso de uma rede, ou seja, de uma ferramenta ou arma, essas próteses culturais que, pelo menos inicialmente, serviam para compensar as deficiências naturais do homem. Embora o uso das armas tivesse aumentado o poder do homem primitivo em relação aos animais de caça, esse avanço não alterava nada no

${ }^{11}$ Principalmente em Ideen zur Philosophie der Geschichte der Menschheit [Idéias sobre a filosofia da história da humanidade], redigido entre 1784 e 1791.

12 BENJAMIN, 1987, p. 81. V. 2. 
pressuposto básico do pensamento mágico, segundo o qual o mundo é habitado por espíritos com poderes próprios: a flor atrai a borboleta e a borboleta engana o caçador mimetizando seu lado humano.

Segundo Max Weber, a diferença entre o homem racional e o "selvagem" não consiste numa quantidade maior de conhecimentos do primeiro em relação ao segundo - muito pelo contrário: o homem primitivo costuma saber muito mais sobre seu mundo que o "civilizado", que, normalmente, não sabe nada do funcionamento do telefone que usa diariamente. A diferença consiste na certeza do primeiro de que, no mundo racionalizado, não há nada que escape ao controle da razão e que esse aparelho não possui vida própria que pudesse resistir à vontade do seu usuário. Para o homem primitivo, entretanto, tudo que ultrapassa o âmbito estreito dos seus conhecimentos, está no poder dos espíritos.

Evidentemente, Weber fala do homem adulto. Como qualquer menino, o protagonista de Infância em Berlim, pelas limitações de sua idade, pelo bem ou pelo mal, não tem como ser um ser racional. A chegada do telefone na casa paterna não é vista por ele como de um processo de racionalização da comunicação que gera economia de tempo e de dinheiro, mas antes de tudo como presença de um objeto estranho com um certo aspecto ameaçador, pois, além de fazer barulho sem um motivo perceptivel, há uma voz que sai do seu interior. Não é a função comunicativa do telefone e a vantagem de superar grandes distâncias que o impressionam, mas sua presença física e o poder que exerce sobre as pessoas da casa. Ocupando o tempo e o espaço dessas pessoas, o telefone não é apenas um 'corpo estranho', algo unheimlich no Heim [= lar] dos pais, mas passa a representar um rival que ameaça sua posição dentro de casa:

A causa pode estar na construção do aparelho ou de minhas recordações - o certo é que, em seu eco, os ruídos das primeiras conversas telefônicas permanecem em meus ouvidos muito distintos dos de hoje. Eram barulhos noturnos. Nenhuma musa os noticiava. A noite da qual procediam, era a mesma que antecedia a todo verdadeiro renascimento. E era uma recém-nascida a voz que dormitava nos aparelhos. A toda hora o telefone era como meu irmão gêmeo $\mathrm{E}$ assim pude vivenciar como triunfou sobre a humilhação dos primeiros tempos de sua carreira briosa. Pois quando lustres, guarda-fogos e palmeiras decorativas, consoles, mesinhas de centro e parapeitos, que então cintilavam nos salões frontais, já estavam há muito estragados e mortos, tal qual um herói lendário, que ficara enjeitado numa garganta entre montanhas, o aparelho, deixando atrás de si o corredor escuro, fez sua entrada real 
nos aposentos iluminados e mais claros, agora habitados por uma geração mais jovem. ${ }^{13}$

No decorrer do tempo, o telefone passa do "corredor escuro" para os "aposentos iluminados", do escuro mítico, quando o aparelho, irmão gêmeo do protagonista, rivaliza com ele, para a luz da razão, quando passa a cumprir uma função bem definida no dia a dia. A vida inteira da Infância em Berlim se passa em espaços mais ou menos fechados, nos quartos da casa, nas chamadas "loggias", uma espécie de varanda, que dão para os típicos pátios berlinenses e, como não bastassem as cavidades das moradias humanas, a rede de esconderijos - há um capítulo próprio intitulado "Esconderijos" é completada pelo Jardim Zoológico com seus diversos setores, túneis e moradas subterrâneas, como no caso da lontra. Além de servir como microcosmo que reflete o macrocosmo humano de Berlim, o Zoológico, apesar de artificial, parece ser uma analogia semi-natural do sistema cultural das habitações berlinenses, que, para a criança, tem mais o aspecto de uma "segunda natureza" do que de uma forma racionalizada da convivência humana.

O dom de reconhecer semelhanças não é mais que um fraco resquício da velha coação de ser e se comportar semelhantemente. Exercia-se em mim por meio de palavras. Não aquelas que me faziam semelhante a modelos de civilidade, mas sim às casas, aos móveis, às roupas. ${ }^{14}$

A lógica da semelhança que Benjamin procura resgatar também através de ensaios como "A doutrina das semelhanças"15 e que, para Foucault, serve como "epistémê" da época anterior à "idade clássica"16 encontra sua terceira analogia no próprio texto que não segue uma lógica linear, mas cuja divisão resulta, na melhor das hipóteses, de certas afinidades. A própria história editorial de Infância em Berlim deixa claro que o autor mudou várias vezes a seqüência dos episódios ${ }^{17}$ e que o livro foge à intenção de muitas

\footnotetext{
13 BENJAMIN, 1987, p. 79. V. 2.

${ }^{14}$ BENJAMIN, 1987, p. 99. V. 2.

${ }_{15}$ BENJAMIN, 1985, p. 108-113. V. 1.

${ }^{16}$ FOUCAULT, 2002. Cap. II - "A prosa do mundo".

17 Somente em 2000 saiu a chamada "versão de Gießen", baseada no último manuscrito da Infância em Berlim de 1938, encontrado em 1981 na Bibliothèque Nationale de Paris; BENJAMIN, 2000.
} 
outras autobiografias de apresentar a própria vida como coerente ou de relacionar os primeiros anos de vida com a idade adulta do narrador, procurando na infância possíveis causas por efeitos posteriores. Também não se trata de uma tentativa de inserir a vida de uma criança de uma determinada condição socio-econômica no seu contexto histórico, fornecendo dados que explicassem os acontecimentos das primeiras décadas do século XX. Com exceção de alguns comentários melancólicos do tipo "Hoje sei andar; porém, nunca mais poderei tornar a aprendê-lo", ${ }^{18}$ o narrador adulto se mantém discretamente à margem do texto, tratando sua infância como um espaço fechado, ou então, como um mundo dividido em vários espaços. Evitando uma racionalização da própria vida inserindoa na lógica do tempo, Benjamin optou por uma solução 'mágica'.

\section{Referências Bibliográficas}

BENJAMIN, Walter. Obras Escolhidas. São Paulo: Brasiliense, 1985. V. I.

BENJAMIN, Walter. Infância em Berlim por volta de 1900. In: Rua de mão única. Obras Escolhidas V. 2. Trad. Rubens Rodrigues Torres Filho, José Carlos Martins Barbosa. São Paulo: Brasiliense, 1987.

BENJAMIN, Walter. Berliner Kindheit um Neunzebnhundert. Gießener Fassung. Frankfurt/Main: Suhrkamp, 2000.

FOUCAULT, Michel. As palavras e as coisas. São Paulo: Martins Fontes, 2002.

FREUD, Sigmund. Das Unbehagen in der Kultur. In: Fragen der Gesellschaft. Ursprünge der Religion. Frankfurt/M.: Fischer, 1974.

SCHILLER, Friedrich. A educação estética do homem. Trad. Roberto Schwarz, Márcio Suzuki. São Paulo: Iluminuras, 1990.

TIEDEMANN, Rolf. Einleitung des Herausgebers. In: BENJAMIN, Walter. Das Passagen-Werk. Frankfurt/Main: Suhrkamp, 1983.

WEBER, Max. Soziologie - Universalgeschichtliche Analysen - Politik. Stuttgart: Kröner, 1992.

${ }^{18}$ BENJAMIN, 1987, p. 105. V. 2. 


\section{Resumo}

Infância em Berlim é o mapeamento "mágico" dos primeiros anos de vida de um autor cuja autobiografia se limita a desenvolver uma topografia infantil, marcada pela magia das passagens clandestinas e dos esconderijos subterrâneos. Ao contrário do discurso autobiográfico tradicional, determinado por uma cronologia mais ou menos linear, o texto se mantém distante dos condicionamentos temporais e históricos, sendo que cada um dos breves episódios é um lugar dentro de uma mundo infantil que resgata as peculiaridades do espaço da criança, antes de sofrer as imposições da idade adulta.

\section{Abstract}

Berlin Childbood Around 1900 is the "magic" mapping of the first years of an author's life whose autobiography is reduced to the child's topography, which is characterized by the magic of secret passages and underground hiding-places. Contrary to the traditional autobiographic discourse, determined by a more or less linear chronology, our text is far from any historical determinism, so that any of the short episodes is a place within a world the rescues the peculiarities of the child's space, before enduring the impositions of the adult age. 